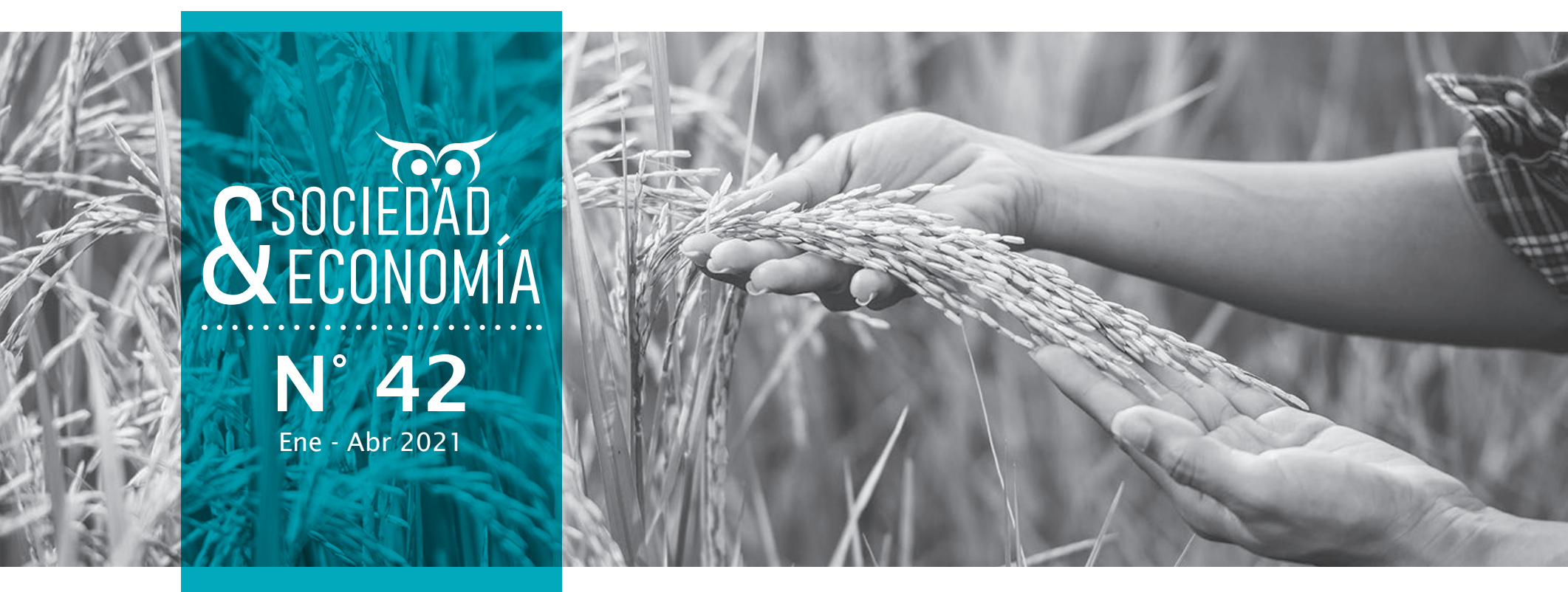

\title{
Objetos diversos, lógicas comunes. Dimensiones políticas y socio-ambientales de la ciencia estatal
}

\author{
Diverse Objects, Common Logic. Political and \\ Socio-Environmental Dimensions of State-Based Science
}

\section{Cecilia Gárgano'}

Consejo Nacional de Investigaciones Científicas y Técnicas, Buenos Aires, Argentina; Universidad Nacional de San Martín, Buenos Aires, Argentina; Universidad de Buenos Aires, Buenos Aires, Argentina.

(a)

(ID)

c.gargano@conicet.gov.ar

http://orcid.org/0000-0002-9594-0075

Guillermo Folguera ${ }^{2}$

Consejo Nacional de Investigaciones Científicas y Técnicas, Buenos Aires, Argentina; Universidad de Buenos Aires, Buenos Aires, Argentina.

guillefolguera@yahoo.com.ar

(ID)

http://orcid.org/0000-0002-4990-7039

Recibido: 09-08-2019

Aceptado: 04-08-2020

Publicado: 15-01-2021

1 Doctora en Historia.

2 Doctor en Biología. 


\title{
Resumen
}

Este artículo estudia en forma comparativa dos trayectorias estatales de investigación en Argentina. Por un lado, la obtención de variedades de arroz resistentes a herbicidas desarrolladas por el principal organismo estatal dedicado a la investigación agrícola. Por otro, la realización de un inventario nacional de glaciares, a cargo de una segunda institución científica estatal. Para este análisis, se utilizaron diferentes fuentes documentales (papers, documentos institucionales y regulatorios, prensa gráfica), y se realizaron entrevistas a científicos, técnicos y pobladores. En conclusión, se encuentra que la misma lógica se aplica en escenarios distintos, donde el Estado y los saberes científico-tecnológicos intervienen de modos variados. Esa lógica está centrada en la promoción de una ciencia estatal de carácter empresarial, que constituye un insumo fundamental para el patrón de acumulación extractivista vigente.

Palabras clave: ciencia estatal; ciencia empresarial; investigación agrícola; glaciología; minería.

\begin{abstract}
This article is a comparative study of two state-based lines of research in Argentina. One involves the development of herbicide-resistant rice varieties by the main state agency devoted to agricultural research. The other is the development of a national inventory of glaciers by another state-run scientific institution. Different document sources were used for this analysis (papers, institutional and regulatory documents, print media), and interviews were carried out with scientists, technicians, and residents. The study found that the same logic was applied to the different scenarios in which the State and scientific-technological knowledge conducted different interventions. That logic focused on promoting commodity-centered science, which constitutes a fundamental input for the current pattern of extractivism.
\end{abstract}

Keywords: state science; business science; agricultural research; glaciology; mining.

\section{Financiación}

La investigación fue realizada en el marco del proyecto PICT, "Ciencia y política”, dirigido por Cecilia Gárgano, financiado por la Agencia Nacional de Promoción de la Investigación, el Desarrollo Tecnológico y la Innovación.

\section{Conflicto de interés}

Los autores declaran no tener ningún conflicto de interés. 


\section{Introducción}

La existencia de múltiples ámbitos donde se desarrollan investigaciones científicas y tecnológicas en Argentina, y su vinculación con numerosas problemáticas sociales y ambientales, ofrece un mapa complejo y heterogéneo. Al mismo tiempo, la producción local de conocimiento se encuentra atravesada por elementos transversales igualmente múltiples, que abarcan desde las dinámicas productivas hasta las voces involucradas en la toma de decisiones y los efectos asociados.

Por otro lado, la existencia de un esquema de acumulación de carácter extractivista que configura la dinámica socio-económica local ha sido ampliamente estudiado (Gómez-Lende, 2019; Manzanal, 2012; Teubal y Rodríguez, 2002; entre otros). Sin embargo, los diversos roles que ocupan los conocimientos científicos y tecnológicos en este esquema constituyen una temática menos explorada. En este sentido, aparece la necesidad de preguntarnos acerca de las lógicas comunes presentes en las prácticas científicas y sus implicancias sociales, económicas, políticas y ambientales.

Este artículo indaga dos casos en clave comparativa. En ambos, el saber científico opera dentro de una trama compleja, que involucra Estado y empresas, contenidos de investigación, dinámicas de acumulación, conflictos sociales e impactos ambientales. Con el objetivo de analizar cómo opera esta dinámica, fueron elegidos dos casos de relevancia local y regional. Mientras el primer caso involucró la obtención y liberación de variedades de arroz resistentes a herbicidas, el segundo caso comprendió la realización del Inventario Nacional de Glaciares. Ambas experiencias son analizadas bajo una misma clave analítica, explorando las vinculaciones entre el saber experto, la producción tecnológica, el accionar de las empresas y el Estado, y la agencia de las comunidades implicadas.

A partir de un trabajo previo (Gárgano, 2018) que se centró en la obtención de estas variedades de arroz, en este artículo profundizamos el análisis de las implicancias políticas y socioambientales de los criterios técnicos impli- cados en esta investigación, y ampliamos en clave comparativa su vinculación a un nuevo objeto de estudio: el relevamiento nacional de glaciares, no trabajado aún en la bibliografía.

Conceptualmente, recuperamos la importancia de la ciencia de corte empresarial generada por el Estado como un insumo clave del agronegocio (Gárgano, 2018), y en términos más generales, la vinculación entre la producción local de conocimiento científico-tecnológico y el esquema de acumulación por desposesión (Harvey, 2003). En términos metodológicos, el trabajo analítico se realizó combinando el relevamiento de fuentes documentales (papers, documentos institucionales y regulatorios, prensa gráfica), con la realización de entrevistas abiertas y semi-estructuradas a científicos, técnicos y pobladores, utilizando el criterio de snowballing o "bola de nieve" para la construcción de las muestras y la identificación de su saturación.

Los ejes analíticos indagados en la reconstrucción de los casos fueron:

i) fundamentaciones presentes en la adopción de los criterios científicos y técnicos considerados;

ii) efectos sociales-ambientales y omisión de peligros;

iii) relaciones involucradas entre Estado, empresas y comunidades científicas;

iv) voces incluidas-excluidas en la definición de las agendas de investigación.

De esta forma, fueron reconstruidas las experiencias seleccionadas, señalando la existencia de racionalidades, problemáticas y disputas comunes.

El recorrido del presente trabajo es el siguiente: en el próximo apartado se ofrece una breve narrativa de ambos casos. El tercero presenta los criterios técnicos y científicos presentes en ambas trayectorias de investigación. El cuarto problematiza esta dimensión, analizando la omisión de peligros potenciales derivados 
de los criterios adoptados. La quinta sección analiza las vinculaciones registradas en ambas experiencias entre el Estado argentino, empresas y científicos. El sexto apartado reflexiona, a partir de este recorrido, en torno a cuáles son las voces que son autorizadas para incidir en la definición de estas agendas de investigación, qué intereses son habilitados en esta dinámica, y cuáles omitidos.

Finalmente, en las conclusiones se puntualizan los principales resultados, argumentando la existencia de una lógica común, y se plantean nuevos interrogantes sobre las relaciones entre ciencia, extractivismo y mercado, en el escenario argentino.

\section{Presentación de los casos}

\subsection{Arroz: entre la alimentación y el agronegocio}

El arroz es uno de los cultivos comerciales más importantes del mundo, siendo Argentina el octavo exportador. Su relevancia para la alimentación y para el negocio de las mercancías agrícolas resume parte del conflicto asociado a las semillas en términos generales. El primer caso indagado se centra, precisamente, en la producción de variedades de arroz resistentes a herbicidas. Este arroz fue generado por el Instituto Nacional de Tecnología Agropecuaria (INTA), institución del Estado argentino, y $\mathrm{Ba}$ dische Anilin und Soda Fabrik (BASF), empresa multinacional de origen alemán.

Creado en 1956, el INTA conserva de su estructura original una cobertura territorial nacional, mediante estaciones experimentales agronómicas y agencias de extensión rural que se distribuyen a lo largo del país.

Por otro lado, Entre Ríos, sede geográfica de la trayectoria que analizaremos, es una de las provincias que registra mayor cantidad de denuncias de fumigaciones de lo que las comunidades en el territorio denominan "agrotóxicos" y, gran parte de la comunidad científica, "fitosanitarios".

En 1996, en una de las estaciones experimentales del INTA ubicada en esta provincia, la Es- tación Experimental Agronómica Concepción del Uruguay, comenzaron las investigaciones para obtener nuevas variedades de arroz. Buscaban generar semillas con resistencia a un grupo de herbicidas, objetivo que cumplieron casi diez años más tarde. El equipo a cargo logró patentar dos variedades. Por un lado, "Puitá INTA CL", una variedad de arroz de ciclo corto, alto rendimiento agrícola y calidad culinaria, fue inscrita en el Instituto Nacional de Semillas (INASE) el 22 de agosto de 2005. Y, por otro, la variedad "Gurí-INTA CL", que fue inscrita en febrero de 2011.

En simultáneo a investigaciones de la Universidad de Louisiana, se sucedieron las del INTA argentino. Con el mismo objetivo, desarrollar semillas de arroz resistente a un herbicida de la familia química IMIs, el INTA realizó un desarrollo similar pero diferente. Obtuvo dos mutantes que logró patentar, demostrando que la mutación alcanzada había sido realizada en otra parte de la secuencia de ADN a la realizada por el equipo estadounidense. La investigación fue realizada en convenio con BASF, a quien el INTA otorgó la licencia comercial de las variedades a nivel mundial, excluyendo a Argentina y Uruguay.

De origen alemán, BASF es una multinacional que, en 2015, cumplió su 150 aniversario. En su larga historia, el eje conductor está dado por su importancia en la industria química, que atraviesa su accionar en ramas tan diversas como los pigmentos, el caucho sintético, los fertilizantes, los plásticos y las fibras sintéticas, los productos farmacéuticos y vitaminas, y los herbicidas (BASF, 2015). Su incursión en investigación y desarrollo en biotecnología vegetal $y$ en el negocio de los herbicidas ha ido en aumento en la última década. Actualmente, el sistema Clearfield es la tecnología comercializada por BASF en convenio con más de 100 empresas semilleras y con organismos oficiales de investigación, incluyendo algunos de América Latina.

La elección de este primer caso responde a tres razones claves. En primer lugar, la relevancia histórica que ha tenido y conserva el sector rural argentino en las dinámicas econó- 
micas, sociales y políticas. En segundo, refiere al lugar preponderante, en términos materiales y simbólicos, que ocupa esta investigación dentro del INTA y en los discursos asociados a su accionar. El convenio implicado en este desarrollo es tomado como ejemplo exitoso de vinculación tecnológica y de la capacidad del organismo, en este caso ligado a la difusión de la genética del INTA (Gárgano, 2018). En tercer lugar, debido a la importancia creciente de los saberes científicos y tecnológicos en el modelo productivo vigente en el agro, y a la necesidad de analizar su rol en las implicancias socioambientales que este esquema conlleva.

\subsection{Glaciares: del inventario al conflicto}

Junto a la producción y exportación de commodities agrícolas, la explotación minera constituye otra de las piezas de un mismo esquema de acumulación de carácter extractivista, que ha avanzado en diversas regiones de Argentina. La provincia de San Juan es uno de estos espacios, en el que destaca el rol de la minera de origen canadiense Barrick Gold, actualmente asociada a la firma china Shandong Gold Group. Se trata de la multinacional dedicada a la extracción de oro más grande del mundo y cuenta con más de 23 minas operativas en Estados Unidos, Canadá, Australia, Chile, Papúa Nueva Guinea, República Dominicana, Zambia, y Argentina. En distintas regiones ha protagonizado escenarios que derivaron en conflictos por la contaminación de aguas y suelos asociada a sus actividades. En algunos casos, se dieron posteriores "remediaciones ambientales", así como numerosas resistencias por parte de movimientos sociales (Newenham-Kahindi, 2011).

En el año 2007, la Comisión de Recursos Naturales y Conservación del Ambiente Humano aprobó una primera ley para la protección de los glaciares y el ambiente periglacial. Fue aprobada por Diputados y un año después también por el Senado. De esta forma, se sancionó la Ley $N^{\circ} 26418$. Poco después, la entonces presidenta Cristina Fernández de Kirchner la vetó a través del decreto 1837/08. Finalmente, el senador Filmus y el diputado
Bonasso presentaron un nuevo proyecto de ley que fue aprobado en el año 2010. La Ley 26.639 de Presupuestos Mínimos para la Preservación de los Glaciares y del Ambiente Periglacial, en su artículo $5^{\circ}$, dispuso la realización de un inventario y monitoreo del estado de los glaciares y del ambiente periglacial, a cargo del Instituto Argentino de Nivología, Glaciología y Ciencias Ambientales (IANIGLA) (Ministerio de Justicia y Derechos Humanos, 2010, Art. 5). Creado originalmente en 1972, el Instituto está organizado internamente en Grupos de trabajo que representan las veintiún principales líneas de investigación en el IANIGLA. Una de ellas fue la que tomó en sus manos la realización del inventario.

A pesar de haber sido promulgada en el 2010, la Ley Nacional de Glaciares no ha sido aplicada en forma integral. Si bien una vez promulgada fijó ciento ochenta días para concluir el inventario en zonas prioritarias, para el 2015 este no estaba completo.

En septiembre de 2015 , se produjo un derrame de cianuro producido por la minera Barrick Gold, que no sería el último. El incumplimiento en la confección del inventario pasó entonces a formar parte de una problemática mayor: en tanto la identificación de glaciares y ambiente periglacial impide la actividad minera en dichas zonas, la ausencia fue interpretada por los residentes de Jáchal como una desprotección al territorio. Tanto la existencia de plazos incumplidos, como los criterios adoptados para su realización, fueron tomados como eje de la causa judicial que impulsa la Asamblea "Jáchal No Se Toca", conformada por habitantes de la ciudad sanjuanina.

Luego de los derrames de cianuro en el río Jáchal en 2015 y 2016, provocados por la actividad desarrollada por la minera Barrick Gold en zonas de glaciares y periglaciares, la Asamblea planteó en los tribunales que el diseño del inventario de glaciares elaborado por el IANIGLA había influido en la posibilidad de los derrames por reducir las áreas protegidas por la ley vigente. Si bien el pedido original apuntó contra la empresa y tenía por objetivo cerrar la mina, por determinación de la Corte Suprema, la 
investigación de los derrames quedó en manos de la Justicia provincial de San Juan, donde fue estancada (E. Viale, comunicación personal, 24 de septiembre de 2019). Sin embargo, desde los tribunales porteños prosiguió otra causa orientada exclusivamente a los funcionarios implicados: Sergio Lorusso -ex secretario de Ambiente de la Nación-, Beatriz Domingorena -ex subsecretaria de Control y Fiscalización Ambiental y Prevención de la Contaminación-, Jorge Mayoral -ex secretario de Minería de la Nación-, y Ricardo Villalba, la máxima autoridad del IANIGLA. Los cargos que se les imputan son abuso de autoridad e incumplimiento de los deberes de funcionario público por vulnerar la Ley Nacional de Glaciares. Es, precisamente, el proceso de realización de este inventario y el accionar científico del IANIGLA nuestro segundo caso de estudio.

Dos aristas de este caso revisten gran interés para nuestros fines. Por un lado, se trata de una experiencia que permite analizar cómo operan saberes científicos y criterios técnicos en una agenda vinculada a uno de los ejes del esquema extractivista: la actividad minera. Por el otro, el conflicto vigente en terreno judicial y en la arena de la sociedad civil ha puesto en evidencia los criterios técnicos utilizados en la realización del inventario, ofreciendo así un escenario privilegiado para el análisis de la construcción de los mismos, los discursos y posicionamientos dentro de la comunidad académica, y su relación con los reclamos de la población afectada.

\section{Criterios técnicos implicados}

\subsection{Criterios técnicos en las investigaciones en arroz}

La obtención de variedades modificadas de arroz que obtuvo el INTA, en convenio con BASF, se basó en la adopción e implementación de dos criterios técnicos. El primero, se refiere directamente a la técnica elegida para generar la resistencia buscada, es decir, a la forma de modificación de la semilla.

\subsubsection{Semilla modificada}

Las variedades desarrolladas fueron obtenidas mediante la técnica de mutagénesis inducida. Esta técnica consiste en inducir mutaciones en el genoma por medio del uso de sustancias químicas o radiaciones, que generan cambios en la planta (ARGENBIO, s.f). En el caso particular aquí analizado, la obtención de variedades mutantes fue inducida químicamente.

Desde mediados del siglo $X X$, la mutagénesis operó obteniendo mutaciones al azar y, a partir de la expansión de la biotecnología, en la década de 1980, incorporó algunas de sus herramientas, como los marcadores moleculares. A diferencia de la transgénesis, esta técnica no implica la incorporación de un gen extraño a la planta. Las primeras líneas de arroz resistentes fueron obtenidas en la década de 1980 por mejoramiento genético, con el uso de agentes mutagénicos (Croughan, 1994). Las variedades de arroz analizadas poseen una mutación en la enzima acetolactato sintasa, que les otorga resistencia a un tipo particular de herbicidas $^{3}$. Tal como fue mencionado, la obtención de esta semilla modificada mediante la técnica de mutagénesis es parte de un paquete tecnológico, que configura todo un sistema de producción. Por esta razón, el segundo criterio relevante en la obtención de esta variedad de arroz corresponde al herbicida asociado.

\subsubsection{Herbicida}

Existen tres tipos de tecnologías utilizadas para inducir la resistencia a herbicidas en arroz. Una de ellas se orienta a la resistencia al glufosinato, el herbicida que es comercializado bajo la marca Liberty Link ${ }^{\circledR}$ por la empresa

3 Se trata de las imidazolinas (IMIs), que pertenecen a la familia de inhibidores de ALS, una enzima de las plantas requerida para la producción de aminoácidos esenciales. Existen cinco clases químicas de herbicidas ALS: sulfonilureas, imidazolinonas, triacil-pirimidinas, pirimidinil-tiobenzoatos y sulfonilamino-carbonil-triazolinonas. Hasta el descubrimiento de las IMIs, el único otro herbicida basado en la interrupción de la síntesis de aminoácidos esenciales era el glifosato. Actualmente, las sulfonilureas y las imidazolinonas son las más extensamente desarrolladas y comercializadas (Shaner y O' Connor, 1991). 
Sociedad y Economía N 42 (Ene - abr 2021) / e-ISSN: 2389-9050

Objetos diversos, lógicas comunes. Dimensiones políticas y socio-ambientales de la ciencia estatal

multinacional Bayer CropScience, actualmente fusionada con la firma Monsanto. La segunda induce resistencia al herbicida glifosato y es vendida con la marca comercial Roundup Ready ${ }^{\circledR}$ por la firma Monsanto-Bayer. Estas dos primeras implican la obtención de variedades transgénicas. Finalmente, la tercera genera resistencia vía mutagénesis a herbicidas de la familia de las imidazolinonas, cuyo herbicida es conocido comercialmente como $\mathrm{Kifix}^{\circledR}$, y es comercializado por la empresa BASF. Esta última opción fue la elegida por el INTA.

El uso de este herbicida está dirigido a combatir un tipo de arroz que es considerado en sí mismo una maleza. Se trata del "arroz rojo", definido como "un arroz no deseado por los productores” (Ortiz y López, 2011, p. 200). Su denominación científica es Oryza sativa spontanea (Ellstrand, 2003). Es una variante que, por ser de la misma especie que el arroz cultivado, es difícil de combatir. La resistencia a herbicidas de la familia química imidazolinonas (IMIs) comenzó a dar resultados a mediados de la década de 1980. Sin embargo, la conformación de un sistema o paquete tecnológico, bautizado "Clearfield" por la firma BASF, recién fue posible luego de la obtención de variedades de arroz resistentes por parte de la Universidad de Louisina, Estados Unidos, y luego por parte del INTA argentino. Este paquete combina herbicidas del grupo "IMI" (imazapir, imazetapir, imazapic e imazamox) con variedades de arroz resistentes a estos.

\subsection{Criterios técnicos en el relevamiento de glaciares}

En el caso del relevamiento realizado por el IANIGLA, nos centraremos en el inventario nacional de glaciares que realizó este organismo. Este inventario, que fue realizado para cumplir con la ley de Glaciares ya mencionada, involucró al menos dos criterios técnicos que despertaron diferentes cuestionamientos y objeciones. El primero de ellos, se refiere al tamaño mínimo de los glaciares que fueron incluidos en el mismo. El segundo, se trata del utilizado para considerar cuáles son los ambientes periglaciares que aparecieron en el inventario y cuáles fueron dejados de lado.

\subsubsection{Glaciares}

Pese a que la ley señalaba que todos los glaciares debían ser inventariados, al realizar el inventario, el IANIGLA decidió tomar un criterio de exclusión. Este criterio estableció un umbral mínimo de 1 hectárea $\left(0,01 \mathrm{~km}^{2}\right)$. Dicha exclusión es especialmente significativa dado que el $96 \%$ de los glaciares de esta región tiene una superficie inferior a $0,01 \mathrm{~km}^{2}$.

Junto a la definición implicada (qué fue entendido por glaciar), y a los impedimentos metodológicos aludidos para poder inventariar glaciares menores a 1 hectárea, un elemento que pesó fuertemente en la implementación de este criterio fue la adopción de estándares científicos internacionales. Países como Suiza, Francia y Canadá utilizan restricciones de tamaño para inventariar sus glaciares. En este sentido, se apeló a convenciones internacionales de escala global. Finalmente, este criterio se sustentó en considerar depreciable el aporte de los cuerpos menores en tanto recurso hídrico. Los criterios técnicos adoptados para la realización del inventario no solo implicaron la exclusión de los glaciares pequeños, sino que también lo hicieron con muchas geoformas del ambiente periglacial.

\subsubsection{Ambiente periglacial}

Otro de los criterios técnicos presente en la realización del inventario, se refiere al utilizado para identificar qué se entiende por ambiente periglaciar y en qué casos son incluidos. En términos definicionales, la ley vigente señala que:

\section{(...) se entiende por ambiente periglacial en la alta montaña, al área con suelos congela- dos que actúa como regulador del recurso hídrico. En la media y baja montaña al área que funciona como regulador de recursos hídricos con suelos saturados en hielo (Mi- nisterio de Justicia y Derechos Humanos, 2010, Art. 2).}

Sin embargo, a pesar de lo señalado, dentro de todo el ambiente periglacial que ampliamente se extiende en la cordillera de los Andes (Tapia-Baldis et al., 2019), solamente se han incluido los glaciares de escombros. Según la definición del IANIGLA (2010), un glaciar de 
escombro es una masa de fragmentos de roca y material fino, que yace en una pendiente $y$ contiene hielo intersticial o un núcleo de hielo macizo, y presenta evidencias de movimiento gravitacional pasado o presente.

De las geoformas del ambiente periglacial, los glaciares de escombros son considerados una expresión de permafrost de montaña, por lo que tienen significancia ambiental. Al igual que otras geoformas, como los protalus rampart o las laderas de solifluxión, está aceptado que tienen hielo. A su vez, hay acuerdo en que tienen importancia hidrológica, aunque en este último punto existen cuestiones a resolver sobre su aporte en cuanto a caudales que entregan, estacionalidad, calidad del agua, escala de influencia, importancia ecológica, etc.

Tenemos ya la descripción de los criterios técnicos implicados en ambos casos (arroz y glaciares). Ahora bien, la elección de todo criterio técnico presupone efectos diversos: ¿cuáles fueron las implicancias socioambientales de estas elecciones?

\section{Omisión de peligros, invisibilización de efectos socio-ambientales}

\subsection{Arroz: ¿campo limpio?}

En el año 2005, INTA liberó la variedad 31 de Clearfield $^{\circledR}$, a la que denominó "Puitá INTA CL", conteniendo una nueva mutación. Mientras que el porcentaje de siembra de esta variedad es creciente en las diversas provincias arroceras argentinas, su crecimiento es particularmente fuerte en la provincia de Santa Fe, donde alcanza un $80 \%$ del arroz cultivado.

El proyecto reconoce en su inicio un nicho comercial vacante: la existencia de variedades de arroz resistentes a este herbicida producido por BASF. Es decir, fueron los investigadores de la agencia estatal quienes le ofrecieron a la empresa realizar la investigación. En este recorrido, se observa cómo fueron criterios utilitarios los que moldearon los objetivos de la investigación y la conceptualización del problema a resolver. En este caso, la propia definición del arroz colorado como maleza, a la que se buscó erradicar generando las variedades resistentes a herbicidas que atacaran este tipo de arroz. Así, según explicaba el investigador responsable:

En el arroz hay un arroz que es colorado. Tiene la capa externa, el pericarpio, de color pigmentado y cuando lo cocinás queda casi negro. En algunas culturas es apreciable, en la mayoría es despreciable, es un inconveniente. Es un arroz como cualquiera, nada más tiene el pericarpio rojo. Es una maleza, por lo tanto. Es decir todo lo que no es deseable en un cultivo es una maleza. Hoy se ve que tiene más polifenoles, pero la verdad es que es indeseable por la presencia de algo oscuro en un plato blanco, es esa la razón. No es que sea ni tóxico, ni nada. Entonces, esa maleza, que es arroz, no puede ser combatida con nada, porque mata al arroz. Las empresas de herbicidas querían dar solución a esa maleza. Las empresas de agroquímicos producen herbicidas para sacar las malezas. Esa maleza era imposible de sacar, entonces había que generar un arroz resistente, inmune, a los herbicidas para poder aplicarlos y eliminar el arroz rojo. Ese era el objetivo de generar resistencia a herbicidas" (A. Livore, comunicación personal, 17 de abril de 2018).

Junto a la conceptualización del problema de investigación y al objetivo manifiesto de la misma (generar un arroz resistente a los herbicidas producidos por las empresas, en particular los de la firma BASF), la elección de la técnica implicada también estuvo guiada por criterios utilitarios, en un sentido mercantil. Si bien la transgénesis en arroz existe, fue descartada como opción por los investigadores del INTA porque comercialmente en muchos países estos cultivos no son aceptados, o bien deben pasar una serie de controles. En palabras de los protagonistas, "Si produzco arroz transgénico, no lo va a comprar nadie" (A. Livore, comunicación personal, 17 de abril de 2018).

En este sentido, la elección metodológica se basó en un vacío regulatorio existente: no existe un marco normativo que regule la producción mutagénica, ni considere sus riesgos 
potenciales. Como señala Pazos (2007), desde la óptica de la industria, la motivación está en desarrollar productos no transgénicos que aseguren los mismos beneficios comerciales que estos, evitando los cuestionamientos y controles a los que se enfrentan los cultivos transgénicos. La motivación de los investigadores de la principal agencia estatal en materia de desarrollo tecnológico, orientado al agro argentino, fue exactamente la misma.

Consultado por los criterios técnicos empleados, el director del equipo de investigación del INTA señalaba: "Si me preguntás cuál es el método que estoy utilizando, es exactamente el mismo de siempre" (A. Livore, comunicación personal, 23 de mayo de 2017). El discurso enfatiza que lo único que diferencia el trabajo actual del realizado décadas atrás son "algunas herramientas que te mejoran la eficiencia del proceso" (A. Livore, comunicación personal, 23 de mayo de 2017). En el relato se remarca que, mientras que en el pasado era necesario esperar y observar el crecimiento de la planta, en la actualidad el uso de marcadores moleculares provistos por la biotecnología simplifica la tarea, mejora tiempos y reduce costos, sin alterar la base del trabajo de mejoramiento. Mientras que anteriormente este estaba basado en el registro de las expresiones visibles (fenotípicas), conocer el fundamento genotípico hoy permitiría hacer la selección de forma más eficiente. El eje continuaría puesto en la necesidad de generar variabilidad, sobre la que se aplica una presión de selección, se avanza en generaciones para obtener la estabilidad, y de allí se logra la variedad.

Este discurso está en línea con la definición que el Consejo Argentino para la Información y el Desarrollo de la Biotecnología (ARGEN$\mathrm{BIO}$ ), creado con el fin de divulgar información sobre la biotecnología, hace de las Ilamadas "técnicas tradicionales". Se trata de un enfoque que podemos calificar de continuista, en tanto genera un relato sin fisuras que comienza con la sedentarización y las primeras prácticas agrícolas, diez mil años atrás, y llega hasta nuestros días con las herramientas biotecnológicas. Según explican en diversos materiales, se trata de mecanismos naturales e inducidos por el hombre que denominan "técnicas tradicionales de mejoramiento vegetal". La técnica elegida por los investigadores del INTA figura, según este esquema, entre las denominadas convencionales. Según reseña ARGENBIO, en la actualidad las herramientas biotecnológicas incorporadas a esta técnica aceleran el proceso volviéndola "una herramienta más segura y eficiente para el mejoramiento de especies" (ARGENBIO, s.f, p. 5). Al igual que en el discurso del investigador del INTA, "precisión" y "rapidez" son dos de las ideas clave. Cabe precisar que los miembros fundadores de ARGENBIO son BASF, Bayer, Bioceres, Dow AgroSciences Argentina, Monsanto Argentina, Nidera, Pioneer Argentina y Syngenta.

En la misma línea, BASF afirma en su sitio web que el sistema de producción Clearfield ha sido desarrollado a través de técnicas de fitomejoramiento convencional, remarcando que "no introduce ADN de otras especies o reinos por lo tanto NO ES un Organismo Genéticamente Modificado, NO PERTENECE al grupo de cultivos Ilamados transgénicos" (BASF, 2011; mayúsculas en original, s.p.).

Sin embargo, si nos concentramos en cómo se obtiene la variabilidad y qué implicancias conlleva, el énfasis en la continuidad entre las prácticas científicas actuales y las tradicionales es notoriamente menor. Los controles para garantizar dicha precisión no están suficientemente claros. Frente a la pregunta por el control de la mutación (esto es, que lo único mutado sea ese nucleótido respecto al resto de la planta), la respuesta del INTA fue: "Si hubo otros cambios en la planta, no lo sabemos hasta que aparece fenotípicamente" (A. Livore, comunicación personal, 12 de diciembre de 2017). En su análisis, Livore asume que el fenotipo es indicador inequívoco de que la única modificación genética que se registró es la del gen en cuestión. Esto introduce dos aspectos que el saber científico actual contradice. Por un lado, que todos los genes generan variaciones visibles. Por otro lado, que las relaciones entre el genotipo y el fenotipo son lineales, sin producir otros efectos que los registrados. No obstante, la relación genotipo-fenotipo dista de ser de ese 
modo ${ }^{4}$. En este sentido, en tanto no se indagan las modificaciones que pueden haber ocurrido en otros lugares del genoma, ni la relación genotipoambiente, se construyen aproximaciones que simplifican los procesos biológicos y omiten peligros potenciales. De hecho, la mayoría de las objeciones que han sido aplicables para los organismos genéticamente modificados son aplicables a los casos mutagenéticos.

Por el contrario, los argumentos de validación encontrados destacan la implementación de técnicas en tanto más eficientes, veloces y seguras. La subordinación de contenidos de investigación a criterios de mercado se traduce en la noción de eficiencia presente en la definición de conceptos y problemas de investigación. Es válido, entonces, preguntarnos acerca de esta subordinación. Si consideramos que estos conocimientos son producidos con fondos estatales y son altamente sensibles para las condiciones de vida de las poblaciones implicadas y para el ambiente, deconstruir esta idea de eficiencia como natural y la única posible aparece como una tarea urgente.

Al igual que sucede en los cultivos transgénicos, las variedades mutagénicas analizadas fueron concebidas para operar dentro de un paquete tecnológico, en tanto fueron modificadas para ser resistentes a un grupo de herbicidas. Tomando solamente datos de las propias cámaras empresariales, que han sido cuestionadas por subestimar sus cálculos, se estima que en Argentina el uso de estos productos, que parte de la comunidad científica denomina "fitosanitarios" y las comunidades afectadas "agrotóxicos", se ha visto incrementado a lo largo de las últimas décadas 8,4 veces (CASAFE, 2018). Al mismo tiempo, su uso repetido ha sido identificado como una de las causantes de la generación de resistencias naturales.

En este sentido, la experiencia de investigación del INTA demuestra que la generación de re-

4 Por ejemplo, el vínculo ADN-ARN-proteínas presenta enormes complejidades a través de procesos celulares como el splicing alternativo. Para una revisión de la bibliografía especializada al respecto, véase Francese y Folguera (2018). sistencias no deseadas originalmente, antes que un mero error, constituye una parte nodal de la generación de estas semillas. Al respecto, el director del equipo señalaba que en un congreso reciente había sido interrogado debido a que estas variedades incrementaron incidentalmente el uso de otros químicos: "me preguntaron si yo no sentía responsabilidad por los fungicidas que se estaban usando" (A. Livore, comunicación personal, 12 de diciembre de 2017). Este cuestionamiento fue respondido señalando dos argumentos. Por un lado, que las ventajas obtenidas compensan los daños colaterales (una nueva resistencia a fungicidas). Por otro, que el equipo ya está generando una nueva investigación que "soluciona" este problema. Se trata de generar una nueva mutación que mantendría los atributos ya generados sumando una nueva resistencia, a otro herbicida. Nuevamente, comerciado por BASF. Así, expresaban: "estamos cerrando otro acuerdo, con otra resistencia que controla a la anterior" (A. Livore, comunicación personal, 12 de diciembre de 2017).

La anécdota expresa dos elementos cruciales. Por un lado, expone una problemática común en la conformación de estos paquetes tecnológicos. Por otro, alude a un aspecto tan relevante como poco explicitado: la responsabilidad de los científicos y técnicos en relación a los impactos de los conocimientos generados.

La conformación del paquete tecnológico expone un proceso creciente de creación de necesidades y generación de dependencias. Las nuevas resistencias no buscadas originalmente son resueltas con un nuevo insumo, ampliando de esta forma el paquete tecnológico y el círculo comercial al mismo tiempo.

Si este circuito expansivo es virtuoso en términos de las ganancias generadas, es igualmente potente en tanto multiplicador de los conflictos ambientales, ya que intensifica el uso creciente de estos productos, en desmedro de daños registrados y peligros potenciales. Las limitaciones ambientales y biológicas del uso de los herbicidas IMIs incluyen el riesgo del flujo de los genes de resistencia desde los cultivares resistentes al arroz rojo a otros, la contaminación de cultivos de las cosechas siguientes por 
persistencia prolongada del herbicida, la generación de toxicidad residual para algunos cultivos de rotación e, incluso, para los sistemas de agua subterránea o superficial (Ortiz y López, 2011 ; Pazos, 2007). Por las propiedades biológicas y fisiológicas compartidas entre el arroz rojo (la "maleza") y el arroz "Clearfield", el cruzamiento entre ambas especies es altamente probable, y ya ha sido señalado que el uso continuo del herbicida a largo plazo hará que los rojos se vuelvan más resistentes, demandando mayores dosis o nuevos insumos químicos (Rosas et al., 2014, p. 4). De hecho, el flujo génico para este tipo de cultivos ha sido confirmado en campos arroceros de Arkansas (Estados Unidos), sur de Brasil y Uruguay (Menezes et al., 2008; Shivrain et al., 2007).

El segundo elemento, la pregunta por la responsabilidad, explicita las acciones y omisiones por parte de las comunidades científicas implicadas y del Estado en sus diversas facetas (desde ser encargado de generar y aplicar los marcos regulatorios, hasta financiar y desarrollar las investigaciones). En este sentido, es relevante señalar que la elección de la técnica (mutagénesis) se debe exclusivamente a los impedimentos comerciales que pesan sobre los cultivos transgénicos.

Asimismo, el vacío regulatorio vigente invisibiliza el hecho de que, al igual que sucede con la abrumadora mayoría de los transgénicos vegetales, tanto en su concepción como en su implementación, el producto (la semilla modificada) y la técnica adoptada, se encuentran imbricadas al agrotóxico que forma parte del paquete.

En el mismo sentido, los daños potenciales son descartados siempre que se haga un "uso responsable de la tecnología" y se sigan las denominadas "buenas prácticas agrícolas" (Rosas et al., 2014, p. 5). Esta justificación omite precisar cuáles son las implicancias intrínsecas al esquema tecnológico generado, a la vez que invierte la denominada carga de prueba. Es decir, obliga a todo aquel que denuncie daños en su salud o territorio derivados de estos paquetes tecnológicos a probar el modo en el que son causados, siendo que debiera exigirse a quienes los generan que, antes de su implementación, demostraran su inocuidad en ambos niveles.
Demostración que, como mencionamos, no solamente no es posible por los grados de incertidumbre implicados, sino también por los efectos ya visibles. Considerando que es el propio Estado argentino el productor y financiador de estos desarrollos, la operación es doblemente grave.

Finalmente, cabe mencionar que estas nuevas variedades de arroz producidas en Argentina reemplazaron la importación de variedades brasileras de libre disponibilidad, y coincidieron con un fuerte proceso de concentración de la tierra y disminución de productores arroceros. Si bien no es posible adjudicarla a su difusión, se trata de procesos simultáneos sobre los que resulta llamativa la ausencia de investigaciones que analicen su interacción. En este sentido, la generación de estas investigaciones no está desvinculada del patrón hegemónico de producción en el espacio rural, ni de sus problemáticas.

En un formato similar al que ocurre hoy con los cultivos transgénicos, las variedades de arroz mutagénico expresan un control creciente de la cadena de producción alimentaria en escasas manos. El actual escenario de concentración que involucra la producción trasnacional integrada de semillas y agrotóxicos es inédito. Allí donde los saberes sirven a la rentabilidad del capital, se multiplican sus efectos nocivos para la organización colectiva de la vida, con sus consecuentes impactos sociales y ambientales.

\subsection{Inventario nacional de glaciares}

En el caso del inventario de glaciares, la omisión de riesgos se hace presente en varios aspectos asociados a las decisiones técnicas que fueron tomadas. Como señalamos, uno de los criterios se basó en excluir los glaciares más pequeños. La justificación de este criterio es diversa y comprende desde continuar con criterios internacionales hasta aspectos de tipo metodológico y funcional. Desde aquellos profesionales que tomaron la decisión de adoptar dicho criterio, la justificación se sostiene en cuatro razones diferentes: a) definicionales, b) metodológicas, c) criterios internacionales, d) aporte al recurso hídrico. 


\subsubsection{Definicionales}

Para Ricardo Villalba (2018), director del IANIGLA,

(...) glaciares menores a una hectárea no existen en el país. Existen pequeños cuerpos de hielo menores de una hectárea, pero no son glaciares, porque un glaciar requiere de un área de acumulación de nieve, de un área de movimiento o transporte del hielo, requiere de un área de ablación, y todo eso no se da en una hectárea (s.p.).

Sin embargo, como señalamos en un inicio, y como el propio resumen de resultados del inventario afirma, "el $96 \%$ de los glaciares de esta región tiene una superficie inferior a $0,01 \mathrm{~km}^{2}$ " (MAyDS e IANIGLA, 2018, p. 9). En estas definiciones, se registran fuertes escenarios de simplificación epistémica que generan omisiones de riesgos directos. Por un lado, la propia geografía local, en la que los cuerpos de agua pequeños son mayoritarios, aparece desdibujada. Por otro, la propia definición de "glaciar" utilizada reduce su significado. En este sentido, la consideración de un glaciar como meramente un cuerpo de agua, parece entrar en tensión con otras acepciones tales como las del ecólogo Raúl Montenegro que lo entiende de otro modo: "en realidad son ecosistemas glaciares, mucho más que hielo" (Montenegro, 2019, s.p.). Independientemente de lo señalado por la ley y por los abordajes de hidrogeólogos, ciertamente alarma la simplificación de ecosistemas enteros.

\subsubsection{Metodológicas}

Las razones definicionales no fueron las únicas señaladas por sus protagonistas para justificar la exclusión de los glaciares pequeños. Lucas Ruiz, investigador del IANIGLA, ha señalado que en esos umbrales de tamaño es difícil diferenciar un cuerpo de hielo perenne de uno que no lo es (Ruiz, 2018). Este aspecto es interesante, pues otros geólogos han marcado que tal imposibilidad no existe. Por ejemplo, Cristian Daniel Villarroel ha afirmado que existen imágenes que permiten ver los cuerpos menores a una hectárea. Avanzando aún más en esta línea, en el fallo judicial existen declaraciones de ex investigadores partícipes del inventario que revelan que fueron instados a borrar cuerpos menores que habían inventariado. En palabras textuales del fallo:
Manifestaron ante este Juzgado que detectaron e inventariaron miles de geoformas que luego de concurrir al "Primer Taller del Inventario Nacional de Glaciares y Ambiente Periglacial" y familiarizarse con la 'metodología de trabajo' propuesta por el IANIGLA tuvieron que 'borrar' (sic) por ser menores a una hectárea. Refirieron que por las características de la zona los cuerpos glaciares y periglaciales allí ubicados eran menores a tal dimensión y 'más de mil seguro' (Poder Judicial de la Nación, 2017, s.p.).

\subsubsection{Criterios internacionales}

Otro de los elementos que se utilizaron para justificar la exclusión de los cuerpos menores de 1 ha fue que otros países, como Francia, Suiza o Canadá, ya habían utilizado criterios de exclusión basados en el tamaño de los cuerpos. En este sentido, se señaló que "no fue una definición caprichosa" sino que estuvo basada "en estándares internacionales" (Villalba, 2017a, s.p.). En otras palabras, se planteó que si bien el inventario era perfectible "no está mal hecho porque cumple con los estándares internacionales" (Ruiz, 2018 , s.p.). En palabras del propio Villalba (2017b): "Como es un trabajo científico-técnico uno tiene que buscar un tamaño determinado (...) que responde a una convención internacional que se fija en todos los inventarios a escala global y tiene razones técnicas" (s.p.). Esta apelación a "razones técnicas" omite explicitar las implicancias de la elección de este criterio en detrimento de otro que contemplara los cuerpos menores, que son mayoritarios en la zona. $\mathrm{Y}$, al igual que en el criterio anterior, la bibliografía especializada muestra desacuerdos respecto a este punto ${ }^{5}$.

En este sentido, encontramos que la apelación a "estándares internacionales", por un lado, oculta la heterogeneidad de posiciones existente $y$, por otro lado, incorpora acríticamente parámetros establecidos para entornos diferentes, su-

5 "Los Alpes, por ejemplo, necesitan inventarios completos hasta de objetos más pequeños que podrían llamarse glaciares. Los errores de menos del $10 \%$ en los Alpes (ciertamente relevantes para la planificación regional de los recursos hídricos) requeririan un inventario de todas las masas de hielo hasta de 0,01 km²" (Bahr y Radić, 2012, p. 768; traducción propia). 
bordinando las particularidades locales a estos. En esta operación, la metodología se fetichiza en tanto deja de estar al servicio de la problemática (Elías, 1998). Al mismo tiempo, como señalara décadas atrás Oscar Varsavsky (1969), la retórica de la pretendida universalidad esconde que esta está definida por relaciones de poder que involucran asimetrías geopolíticas y económicas, cuyo principal resultado consiste en la generación de agendas de investigación signadas por la dependencia cultural en materia científica y tecnológica. Así, la justificación basada en la adopción de criterios aceptados internacionalmente no solamente no agota la cuestión, sino que es parte fundamental del problema, debido a las implicancias sociales y ambientales que conlleva para el escenario local.

\subsubsection{Aporte como recurso hídrico}

El último aspecto esgrimido, que sostiene el criterio de exclusión de los cuerpos menores, es que su contribución como "recurso hídrico es mínimo" (Villalba, 2018 , s.p.).

En todos los casos, la conclusión es la misma: una disminución de la cantidad de glaciares inventariados, sumado a la total exclusión de los suelos congelados y otras geoformas del ambiente periglacial, y por ende, una mayor posibilidad de incrementar la cantidad de explotaciones mineras con el consiguiente efecto social y ambiental. Nuevamente, es interesante señalar que, dentro de las comunidades profesionales asociadas a estas temáticas, no hay total acuerdo en cuanto a que el criterio de exclusión de los cuerpos menores sea el señalado. Por ejemplo, en un trabajo reciente de autores de América del Norte se señala:

(...) los errores del $1 \%$ y a veces incluso del $10 \%$ del volumen total requieren de inventarios con masas de hielo sorprendentemente pequeñas, en algunos casos moviendo el límite semántico entre glaciares y parches de nieve. A estas escalas, la diferencia entre los glaciares y los parches de nieve se vuelve borrosa, y el inventario debe estar efectivamente completo al 100\% (Bahr y Radić, 2012, p. 764; traducción propia).

Esta diversidad de posiciones respecto a los criterios que se asumen nunca fue señalada, aun cuando las consecuencias que se toman no son menores dada la cantidad de cuerpos excluidos. Más aún, en todos los casos se decidió no considerar las consecuencias que podía tener la exclusión de un cuerpo, por ejemplo en términos de contaminaciones y derrames. Villalba (2018) dice al respecto:

\begin{abstract}
(...) es muy claro que no existe ninguna relación entre el tamaño de los glaciares y la ocurrencia de estos derrames. La ocurrencia de estos derrames son problemas técnicos e ingenieriles de una empresa que está trabajando en este sector, y de la falta de control, por parte de las autoridades competentes de la provincia de San Juan, sobre cómo trabajan estas empresas (s.p.).
\end{abstract}

En un sentido similar, remarcó que "no se puede pensar que el IANIGLA es responsable de los derrames porque no controló a las empresas mineras. Eso no es nuestra responsabilidad" (Villalba, 2018, s.p.). Sin embargo, la Asamblea Jáchal No Se Toca denunció precisamente este punto. Es decir, que la exclusión de los cuerpos menores incumplió la Ley de Glaciares (del año 2010). Puntualmente, su artículo 2 que insta a inventariar todos los glaciares “... cualquiera sea su forma, dimensión y estado de conservación" (Ministerio de Justicia y Derechos Humanos, 2010, Art. 2). Y señaló que, sin esta exclusión realizada por el IANIGLA, los derrames de cianuro (del año 2015) no hubiesen ocurrido, ya que la actividad minera no hubiese podido proseguir por estar en una zona prohibida por la ley (Viale, 2017).

En lo que refiere al otro criterio técnico que se adoptó, tal como vimos en la sección 3.2, tiene que ver con la consideración de inventariar únicamente a los glaciares de escombros entre el ambiente periglacial. Respecto a este criterio, dos estrategias de omisión pueden reconocerse.

La primera de ellas, radica en una inversión de la carga de prueba. Se expresa en que la funcionalidad como recurso hídrico debe verificarse para que sea incluido en dicho inventario, y no que deba protegerse hasta en tanto se concluya que no posee agua. La justificación de esta decisión radica en que se tratan de las 
únicas geoformas periglaciares en las que estaría comprobado que actúan como reservas de agua. Esto no descarta que otras geoformas puedan tenerlo, por lo que se trata de una explícita inversión de la carga de prueba. Este mecanismo está presente en otras problemáticas ambientales en el caso de Argentina, siendo una de las más reconocidas la necesidad de verificar los efectos tóxicos de diferentes agroquímicos. Verificar para proteger.

Nuevamente, la diversidad de posiciones es una norma y no una excepción. Carlos Seara, hidrogeólogo cordobés crítico a la postura adoptada en este inventario, remarca la necesidad de contemplar el ambiente periglacial e introduce a las presiones derivadas de la actividad minera en el centro de la cuestión:

(...) el ambiente periglacial está defendiendo directamente al ambiente glaciar. Si hoy los glaciares están retrocediendo ¿qué pasará cuando les quitemos esa defensa periglacial, con infraestructura, con actividades económicas como la minería? Las comunidades se nutren del agua que proviene de la Cordillera y si esto avanza el problema lo vamos a ver inmediatamente transferido a las economías regionales de la zona. Es un problema real que ha surgido como consecuencia de las presiones de gobiernos provinciales que ven que en esas zonas no van a poder intervenir las multinacionales mineras con quienes ellos están casados. Los problemas que se argumentan para vetar la ley son en realidad presiones, porque el espacio que ocupa el sistema periglacial dentro de nuestra Cordillera está en el orden de la sexta parte de todo el territorio de montaña, que es una constante a nivel mundial. En esa superficie ¿cuántos yacimientos tendremos? (Seara, citado en Rodríguez-Pardo, 2010, s.p.).

Otras posiciones remarcan la necesidad de prestar atención a la especificidad de la región, y a la importancia singular que tiene el ambiente periglacial en los Andes Áridos.

Entre la exclusión a priori y la inversión de la carga de prueba, gran parte de los cuerpos presentes fueron sacados del inventario. La menor cantidad de geoformas y su consideración aislada tienen consecuencias directas tantos sociales como ambientales, entre las que se destaca la menor cantidad de agua disponible como la contaminación de diversos cuerpos de agua. No son riesgos de lo desconocido, sino riesgos que se elige no conocer.

\section{Estados, empresas, comunidades científicas}

El extractivismo en Argentina, en tanto forma específica de explotación y apropiación de la naturaleza, constituye un esquema de acumulación de implicancias políticas y económicas particulares. Basado en un binomio constituido entre los poderes financieros transnacionales y los gobiernos locales, ha dado como resultado un patrón concentrador y excluyente, con altos costos sociales y ambientales (Manzanal, 2012). En este esquema, el agronegocio y la actividad minera a gran escala ocupan posiciones fundamentales. ¿Qué ocurre, entonces, con la producción de conocimiento científico y tecnológico en relación a esta dinámica? Y, en particular, ¿qué características asume la relación entre el Estado, los científicos y los capitales privados en los dos casos analizados?

\subsection{Arroz resistente}

Los saberes científicos y tecnológicos producidos en ámbitos estatales de investigación constituyen un insumo fundamental en la obtención y expansión de los cultivos modificados. Por esta razón, cabe detenernos en cómo son producidas la ciencia y la tecnología que intervienen en este proceso. En este sentido, el carácter empresarial ya señalado en el análisis de los criterios, objetivos y contenidos de la investigación, posee otra dimensión.

Como indicamos, la investigación realizada por el INTA fue hecha como parte de un Convenio de Vinculación Tecnológica (CVT) con la empresa BASF. Bajo esta denominación, se alude a la articulación entre organismos estatales de investigación y empresas privadas. Los CVT en Argentina datan de fines de la década de 1980 y se enmarcan en un proceso internacional de privatización del conocimiento científico y tec- 
nológico producido en organismos oficiales y universidades (Gárgano, 2018). En estos convenios, la empresa (muchas veces transnacional, también de capitales nacionales) financia parte del proceso de investigación. Los resultados suelen permanecer nominalmente como propiedad intelectual del organismo y equipo que los generó, y habitualmente son explotados comercialmente por parte del sector privado, que retribuye con algún porcentaje de regalías estipulado. En cuanto a los objetivos de las investigaciones, son definidos mayoritariamente en función de necesidades corporativas de las empresas implicadas y de la potencial rentabilidad esperada.

Las cláusulas del CVT, celebrado entre INTA y BASF, incluyen la cesión de la explotación comercial de las variedades a nivel mundial, exceptuando su comercialización en Argentina y Uruguay. Obviamente, los términos implican una participación asimétrica de las partes en las ganancias millonarias obtenidas por la empresa. En cuanto a lo percibido por el sector estatal, a través del INTA, estas regalías no son redirigidas dentro del gasto público, sino que sostienen la continuidad del programa de investigación del organismo. Esto coincide con la tesis de Gómez-Lende (2019, p. 92) acerca de la sobrestimación de la capacidad del Estado de captar excedente a través del agronegocio.

Al mismo tiempo, como analizamos previamente, toda la conformación de la agenda de investigación realizada por el organismo estatal responde a la identificación de un nicho comercial vacante, de relevancia estratégica para la multinacional de origen alemán. Paradójicamente, dentro de las validaciones señaladas por investigadores y funcionarios, la retórica exalta el aporte nacional identificado con la capacidad del INTA de difundir en el mundo la mejora con base genética obtenida por sus investigadores (Gárgano, 2018). Curiosa construcción de la nacionalidad que parece restringirse al espacio físico (una institución oficial) y su sello institucional. Sin embargo, las fronteras, materiales y simbólicas, se presentan lábiles y difusas.

¿A qué se refiere entonces la denominación de lo "público" en esta articulación? El sistema de consorcios o convenios, del que este caso es simplemente una muestra, es denominado habitualmente como una estrategia de "cooperación público-privada". Esta retórica, que equipara "público" a "estatal", omite precisar cuál es el rol del Estado en este esquema de acumulación en general, y en la producción científico-tecnológica implicada en el agronegocio en particular. Mientras que el eje de lo público podemos entenderlo como un ámbito de lo común, donde están incorporadas necesidades y problemáticas ligadas al bienestar de las poblaciones implicadas, la agencia estatal en este proceso garantiza un esquema concentrador y excluyente. Estado, empresas y científicos operan así en un mismo entramado.

\subsection{Inventario de glaciares}

Los conocimientos científicos y técnicos vinculados directa o indirectamente a la actividad minera también involucran entramados en los que el Estado juega un papel clave. Al mismo tiempo, en los casos en los que fue necesaria la difusión de datos científicos oficiales a nivel poblacional estos estuvieron ausentes. Por ejemplo, al momento de producirse el derrame, el 12 de septiembre de 2015 , en el río Jáchal, ningún funcionario se hizo presente. Al decir de uno de los integrantes de la Asamblea y residente de Jáchal, había un "vacío de información", ya que ni siquiera sabían si podían dejar que los animales tomaran agua del río el día siguiente al derrame (Saúl, asambleísta, comunicación personal, 21 de abril de 2019). La empresa fue multada con 40 millones de pesos, en concepto de compensación. Pese a que la Asamblea de Jáchal solicitó que fueran invertidos en el tratamiento del agua, el dinero fue usado en la construcción de cabañas turísticas y la organización de eventos provinciales.

El sector minero ha sido uno de los espacios en donde el accionar estatal ha operado en forma más explícita, como garante de estas actividades y sus tasas de rentabilidad. De manera creciente, instituciones estatales, tales como el Servicio Geológico Minero Argentino (SEGEMAR), han ido cediendo a los intereses privados en una operación que ha hecho de la minería una auténtica política de Estado (Schiaffini, 2004; 2017). 
Por otro lado, en el año 2006, antes de que fuera promulgada la actual ley que protege los glaciares, investigadores del mismo IANICLA realizaron un estudio de impacto ambiental en el que sí fueron incluidos cuerpos menores. En aquella oportunidad, el estudio fue hecho a pedido de la minera Barrick Gold. Si bien los especialistas que participaron lo hicieron en calidad de investigadores de este organismo, y de otros oficiales como el CONICET, en declaraciones posteriores se ha insistido en que no fue un accionar institucional, sino a título individual. Finalmente, el proceso de control del territorio por parte de las empresas mineras es tal, que son estas las que monopolizan el acceso a los caminos en la cordillera, la gran mayoría construidos a instancias de esta actividad. La realización del inventario no fue ajena a esta situación. Según relata una de las participantes, para realizar estudios de campo, en áreas donde se desarrollan los ambientes glacial y periglacial, en San Juan, "en la mayoría de los casos, se precisa contar con autorizaciones de los dueños del caminos, para las cuales se demanda un equipamiento que es muy difícil de costear para investigadores independientes" (A.P., comunicación personal, 7 de diciembre de 2018). En el mismo sentido, otro de los participantes señala que se alojaban en campamentos que son propiedad de la empresa minera, que aportaba también otros elementos como combustible y comida (C. D., comunicación personal, 7 de diciembre de 2018). Lo cierto es que los lazos entre los capitales mineros y los ámbitos estatales son estrechos, y esta cercanía no deja al margen al ámbito científico.

\section{6 . Voces incluidas, voces silenciadas}

¿Cuáles son las voces autorizadas en la definición de estas agendas de investigación? ¿Cuáles invisibilizadas? ¿Qué nos dice esta configuración? En ambos casos encontramos procesos de jerarquización y exclusión de saberes, que se despliegan tanto al interior del campo científico y tecnológico, como fuera de él.

En el caso de las variedades de arroz desarrolladas por el INTA, por un lado se observa la construcción de ingenieros agrónomos y biotecnólogos como expertos, con nula participación de otros campos disciplinares. Al mismo tiempo, dentro de estos perfiles profesionales, existe un claro predominio de algunos enfoques sobre otros. Por ejemplo, no existe interacción con conocimientos provenientes de las ciencias ambientales o la ecología. Menos aún, diálogo con aquellos provenientes de las ciencias sociales o la medicina, por mencionar algunos de los potenciales implicados en una agenda de estas características.

A su vez, en el proceso de realización del inventario nacional de glaciares llevado a cabo por el IANIGLA, la construcción de los glaciólogos, en tanto expertos, posee tensiones explícitas en relación con la heterogeneidad de criterios implicados y con cuestionamientos provenientes dentro del propio campo disciplinar. Así, no son pocas las voces que insisten en señalar que los glaciares más pequeños son los más sensibles a cambios ambientales, por lo que ante aumentos de temperaturas son los que primero tienden a nutrir las cuencas hidrográficas (Bahr y Radić, 2012; Leiva et al., 2008); de allí la importancia de inventariarlos. Y en cuanto a la imposibilidad metodológica de hacerlo, también se ha señalado que las imágenes de alta resolución espacial de toda la última década, tales como imágenes SPOT, disponibles en Argentina, permiten el reconocimiento de glaciares menores a una hectárea con alta confiabilidad (Leigh et al., 2019). Lejos de reconocer esa diversidad, lo que se presenta de manera frecuente son deslegitimaciones a las posiciones críticas. En este sentido, nuevamente Rodríguez Pardo señala que "No sorprende que casi todos los glaciólogos se desautoricen mutuamente (...) Y de paso relegan opiniones del resto de la población que vive expectante su futuro" (Rodríguez-Pardo, 2010 , s.p.); cuyos cuestionamientos son minimizados aludiendo su carencia de un saber docto o experto. En este punto, entonces, se explicitan las tensiones hacia afuera del campo científico. Como veremos, estas fronteras no son absolutas.

Siguiendo con el caso del inventario, la comunidad de Jáchal, constituida en Asamblea, realizó cuestionamientos a los criterios adoptados, 
que llevó a los tribunales. Este accionar es parte de un movimiento mayor de resistencia a la actividad minera en la zona, que fue intensificado a partir de los derrames de cianuro producidos en el río Jáchal y aledaños. Como parte de esta lucha, se acudió a un reconocido hidrogeólogo extranjero, Robert Morán. En tanto experto, fue contratado para realizar un informe de impacto ambiental que consta en la causa judicial. Para financiar su viaje y trabajo, la Asamblea organizó rifas, peñas y ferias. Acudieron a él por su prestigio internacional, y ante la dificultad de contar con expertos locales, ya que en palabras de un asambleísta: "acá ningún geólogo quería" (S. Domínguez, comunicación personal, 20 de abril de 2019). En esta operación, se vislumbra un doble significado. Por un lado, aparece como una estrategia de autolegitimación, a partir de un saber reconocido como hegemónico (el científico). Según uno de sus abogados, se trató de "tomar el lenguaje del otro" (E. Viale, comunicación personal, 11 de noviembre de 2019). Al mismo tiempo, se evidencia cómo la propia experiencia de vida en el territorio solamente es validada a través de la intervención de una voz autorizada. Un experto extranjero que dijo en su propio lenguaje aquello que la comunidad venía alertando.

Algo similar, aunque en sentido opuesto, ocurrió con la realización del inventario. Cuando distintos pobladores se hicieron presentes en el IANIGLA manifestando sus cuestionamientos, estos no fueron atendidos y, a su vez, no recibieron la presencia de autoridades ni investigadores del instituto en ninguna oportunidad. La omisión de las voces de la comunidad local aparece así como un elemento central.

En el caso de las variedades de arroz, ¿qué voces intervinieron en la definición de la agenda? EI INTA es un organismo estatal cuyo órgano directivo, que aprueba y define sus planes de trabajo, está integrado por representantes del Ejecutivo Nacional, de las Facultades de Agronomía y Veterinaria de las universidades nacionales, y de las principales corporaciones agropecuarias del país. Al mismo tiempo, su política de vinculación tecnológica ha fomentado la articulación con corporaciones transnacionales semilleras y agroquímicas, como en el caso es- tudiado con la participación de BASF. Quienes no forman parte de la definición de las prioridades son aquellos sujetos sociales agrarios que, desde hace décadas, constituyen la contracara del modelo vigente.

Si bien está asentado en la producción de soja transgénica, la expansión de la frontera agrícola en arroz (y en maíz) ha generado problemáticas comunes, operando como vector secundario del extractivismo agrícola intrínseco al modelo sojero (Gómez-Lende, 2019, p. 91). Esta matriz productiva ha producido la desaparición de explotaciones menores, concentrado la propiedad de la tierra, generado desmontes e inundaciones, pérdida de la biodiversidad y múltiples patologías en salud asociadas a las fumigaciones con agrotóxicos (Gómez-Lende, 2019). El accionar de este organismo estatal está ligado a este patrón productivo que usa al territorio como un mero recurso. Investigaciones como la reseñada traducen una necesidad corporativa (en este caso, propia de la firma BASF) como una necesidad local. Aquellos que no definen las prioridades, ni tienen voz en la agenda de investigación oficial, solo padecen sus consecuencias.

\section{Conclusiones: objetos diversos, lógicas comunes}

El carácter empresarial del Estado ha adquirido una faceta particular a partir del esquema neoliberal, impulsado a nivel mundial desde mediados de la década de 1970 y consolidado en la de 1990 (Harvey, 2007). En este tránsito, la producción de ciencia y tecnología desde ámbitos estatales ha acompañado y, en buena medida, colaborado con este proceso, modificando sus propias prácticas e intensificando su carácter mercantil. En este sentido, tal como comenzara afirmando una de las entrevistas iniciales, ¿asistimos hoy a la misma forma de producir conocimiento que hace sesenta años atrás? Las respuestas involucran dimensiones diferentes, que operan en conjunto.

La creciente mercantilización de las investigaciones producidas con fondos públicos ha sido señalada como un proceso en ascenso desde la década de 1980 (Pestre, 2002). En los casos 
aquí analizados también es necesario reparar en el trinomio Estados, empresas, científicos.

En Argentina, este entramado está atravesado por una matriz productiva asentada en la explotación extractiva en general, y en el agronegocio y en la actividad minera en particular. En este marco, en el que resulta difícil y peligroso delimitar "contextos" de la producción del conocimiento y sus propias trasformaciones, es que incluimos los cuestionamientos en torno a las trayectorias de investigación analizadas.

Los casos estudiados exponen que los contenidos de las investigaciones, las racionalidades imperantes, regulaciones implicadas, políticas públicas asociadas y dinámicas de producción y apropiación de conocimientos, son parte de una misma trama que construye y a la vez orienta la producción científico-tecnológica. En esta dinámica, identificamos el accionar de un saber experto que opera generando exclusiones de otros saberes, tanto al interior de las comunidades científicas, como fuera de ellas.
El análisis de los criterios técnicos utilizados en ambas trayectorias posee puntos de contacto en relación con la omisión de peligros y efectos socio-ambientales. Asimismo, observamos convergencias en las voces implicadas (y omitidas) en la definición de las agendas. Al mismo tiempo, se evidencian articulaciones relevantes entre la producción de los conocimientos estudiados y los esquemas extractivos implicados.

En este aspecto, en el caso de las variedades de arroz desarrolladas por el INTA en convenio con BASF, los resultados de la investigación funcionan claramente como insumos nodales del esquema del agronegocio. Por el contrario, en cuanto al inventario nacional de glaciares, la relación no es lineal. Sin embargo, los criterios utilizados han redundado en una desprotección del territorio que, incidentalmente, ha favorecido la actividad minera, en perjuicio de los reclamos de sus habitantes.

La Tabla 1 resume los puntos de contacto entre ambas experiencias analizadas.

\begin{tabular}{|c|c|c|}
\hline \multicolumn{3}{|c|}{ Tabla 1. Resumen de los resultados } \\
\hline & Arroz Mg & Glaciares \\
\hline Privilegio del saber experto & Sí & Sí \\
\hline $\begin{array}{l}\text { Criterios técnicos: omiten } \\
\text { peligros potenciales }\end{array}$ & $\begin{array}{l}\text { Simplificación y determinismo en la } \\
\text { relación genotipo-ambiente. Mutación no } \\
\text { controlada. Generación de nuevas } \\
\text { resistencias }\end{array}$ & $\begin{array}{l}\text { Temporalidad, alcance y construcción de } \\
\text { las definiciones omiten reservas locales de } \\
\text { agua }\end{array}$ \\
\hline Estado-empresas involucrados & INTA-BASF & IANIGLA-CONICET- Barrick Gold \\
\hline Áreas científicas priorizadas & Agronomía, Biotecnología & Glaciología \\
\hline Marco regulatorio & $\begin{array}{l}\text { Manual BPA } \\
\text { Vacío legal }\end{array}$ & Ley Nacional de Glaciares \\
\hline Áreas científicas excluidas & $\begin{array}{l}\text { Ambientales } \\
\text { Ecología } \\
\text { Evolución } \\
\text { Medicina } \\
\text { Ciencias sociales }\end{array}$ & $\begin{array}{l}\text { Ambientales } \\
\text { Medicina } \\
\text { Ciencias Sociales }\end{array}$ \\
\hline $\begin{array}{l}\text { Relaciones escenario } \\
\text { local-internacional }\end{array}$ & $\begin{array}{l}\text { Derechos de comercialización cedidos a } \\
\text { nivel mundial (excepto Argentina y } \\
\text { Uruguay) }\end{array}$ & Aplicación de estándar internacional \\
\hline $\begin{array}{l}\text { Ciencia y patrón de } \\
\text { acumulación local }\end{array}$ & Ciencia, tecnología y agronegocio & Ciencia y extractivismo minero \\
\hline Resistencias sociales & $\begin{array}{l}\text { Transversal: } \\
\text { Organizaciones sociales vs. Agrotóxicos }\end{array}$ & $\begin{array}{l}\text { Activa y específica: } \\
\text { Asamblea Jáchal No Se Toca }\end{array}$ \\
\hline
\end{tabular}


En el caso de la obtención de variedades resistentes de arroz desarrolladas por el INTA, la apelación a una eficiencia mercantil, presentada en forma universal para "los productores", desdibuja que existe una operación de construcción de un tipo particular de eficiencia y una elección de determinados destinatarios como beneficiarios de la agenda. Si, por el contrario, se explicita el interrogante en torno a cuánta utilidad le reportan a las comunidades rurales la producción de variedades modificadas para ser resistentes a un herbicida producido por una firma transnacional, y las implicancias sociales y ambientales de la configuración de este paquete tecnológico, el escenario se complejiza.

Del mismo modo, la forma en que se realizó el inventario nacional de glaciares recuerda que mientras lo que a nivel global puede ser depreciable, a escala local es clave.

En torno a la producción tecnológica y al rol de los profesionales, resulta oportuno retomar la propuesta del pensador austríaco Iván Illich sobre un control lego de la tecnocracia, orientado a una construcción comunitaria de un perfil tecnológico. En este enfoque, democratizar las dimensiones tecnológicas está imbrica- do a un control social de la producción (Illich, 1981). En los casos analizados, su vigencia es clave, en tanto se trata de prácticas que afectan directamente las condiciones de existencia de las comunidades implicadas.

¿Qué nos dicen, finalmente, estas trayectorias del mapa actual de la producción de ciencia y tecnología en Argentina? Poco, si son pensadas en función de sus especificidades. Sin embargo, las problemáticas transversales que recorren generan, al menos, una señal de alarma. Mientras que se construyen explicaciones lineales que, en buena medida, barren con la diversidad al interior de los propios campos científicos, se produce una ciencia empresarial que poco tiene que ver con las necesidades locales, también heterogéneas.

Mientras que el extractivismo hace de los territorios meros recursos confinados a incrementar ganancias privadas, la organización de los conocimientos científicos, en articulación a este esquema, anula su vinculación con preguntas colectivas que cuestionen cómo están siendo habitados, producidos, contaminados y configurados estos espacios vitales. Que interroguen, en definitiva, cómo queremos vivir.

\section{Referencias}

ARGENBIO -Consejo Argentino para la Información y el Desarrollo de la Biotecnología-. (s.f.). Por qué Biotecnología, Cuaderno 5. http://porquebiotecnologia.com.ar/index. php?action $=$ cuaderno\&opt $=5$ \&tipo $=1$ \&note $=5$

Bahr, D. B. y Radić, V. (2012). Significant contribution to total mass from very small glaciers. The Cryosphere, 6, 763-770. https://doi.org/10.5194/tc-6-763-2012

BASF. (2011). Kifix. http://www.agro.basf.com.ar/clearfi eld/clearfield.htm

BASF. (2015). Historia de BASF. La química que une. 1856-2015. https://www.basf.com/es/documents/ es/aboutus/Historia/Libro_Historia_BASF_150_Aniversario.pdf

CASAFE -Cámara de Sanidad Agropecuaria y Fertilizantes-. (2018). Datos del mercado argentino de fitosanitarios. https://www.casafe.org/publicaciones/datos-del-mercado-argentino-defitosanitarios/

Croughan, T. (1994). Herbicide resistant rice (ponencia). 25th Rice Technical Working Group Meeting, Nueva Orleans, Estados Unidos.

Elías, N. (1998). La civilización de los padres y otros ensayos. Norma.

Ellstrand, N. (2003). Dangerous Liasons: When Cultivated Plants Mate with Their Wild Relatives. The 
Johns Hopkins University Press.

Francese, C. y Folguera, G. (2018). Saberes simplificados, tecnociencia y omisión de riesgos. El caso de los organismos genéticamente modificados. RUNA, 39(2), 5-27. https://doi.org/10.34096/runa. v39i2.4251

Gárgano, C. (2018). Ciencia, Tecnología y Mercado: Investigaciones en Arroz en el INTA Argentino. Journal of Technology Management \& Innovation, 13(1), 75-83. http://dx.doi.org/10.4067/S071827242018000100075

Gómez-Lende, S. (2019). Modelo extractivo en Argentina (1990-2016): ¿del extractivismo clásico neoliberal al neoextractivismo progresista? Tres estudios de caso. Sociedad y economía, (36), 82105. https://doi.org/10.25100/sye.v0i36.7458

Harvey, D. (2003). The new imperialism. Oxford University Press.

Harvey, D. (2007). Breve historia del neoliberalismo. Akal.

IANIGLA -Instituto Argentino de Nivología, Glaciología y Ciencias Ambientales-. (2010). Inventario Nacional de Glaciares y Ambiente Periglacial: Fundamentos y Cronograma de Ejecución en cumplimiento con lo establecido por la Ley 26.639 de Presupuestos Mínimos para la Preservación de los Glaciares y del Ambiente Periglacial. IANIGLA-CONICET.

Ilich, I. (1981). Profesiones inhabilitantes. En I. Illich, I. Zola, J. Mc Knight, J. Caplan y H. Shaicken (Comps.), Profesiones inhabilitantes (pp. 9-37). Hermann Blume. https://es.scribd.com/doc/187776401/ Profesiones-inhabilitantes-Ivan-Illich-pdf

Leigh, J. R., Stokes, C. R., Carr, R. J., Evans, I. S., Andreassen, L. M. y Evans, D. J. A. (2019). Identifying and mapping very small $(<0.5 \mathrm{~km} 2)$ mountain glaciers on coarse to high-resolution imagery. Journal of Glaciology, 65(254), 873-888. https://www.doi.org/10.1017/jog.2019.50

Leiva, J. C., Cabrera, G. A., Casteller, A., Novello, V. L. y Corvalán, E. (2008, 26-30 de agosto). El monitoreo de pequeños glaciares andinos entre los $29^{\circ}$ y $32^{\circ}$ de latitud Sur (ponencia). VII Encuentro Internacional de Investigadores del Grupo de Trabajo de Nieves y Hielos de América Latina PHI UNESCO, Manizales, Colombia. http://hielosynieves.atwebpages.com/Resumenes/Argentina_Peque\%C3\%B1 osGlaciares.pdf

Manzanal, M. (2012). Poder y desarrollo. Dilemas y desafíos frente a un futuro ¿cada vez más desigual? En M. Manzanal y M. Ponce (Orgs.), La desigualdad ¿del desarrollo? Controversias y disyuntivas del desarrollo rural en el norte argentino (pp. 17-49). Ciccus.

MAyDS -Ministerio de Ambiente y Desarrollo Sustentable- e IANIGLA -Instituto Argentino de Nivología, Glaciología y Ciencias Ambientales-. (2018). Resumen ejecutivo de los resultados del Inventario Nacional de Glaciares. http://servicios.infoleg.gob.ar/infoleglnternet/anexos/310000-314999/311356/res358$01 . \mathrm{pdf}$

Menezes, V., Mariot, C. y Kalsing, A. (2008). Controle de escapes de arroz-vermelho no sistema de produção Clearfield em arroz irrigado (ponencia). Actas del XXVI Congresso Brasileiro da Ciência das Plantas Daninhas y XVIII Congreso de la Asociación Latinoamericana de Malezas, Ouro Preto, Brasil.

Ministerio de Justicia y Derechos Humanos. (2010). Ley 26.639. Régimen de Presupuestos Mínimos para la Preservación de los Glaciares y del Ambiente Periglacial. http://servicios.infoleg.gob.ar/infoleglnternet/ anexos/1 70000-1 74999/1 741 17/norma.htm\#: :text=La\%20presente\%20ley\%20establece\%20los,de\%20 cuencas\%20hidrogr\%C3\%A1 ficas\%3B\%20para\%20la

Montenegro, R. (2019, 6 de junio). Los glaciares son una caja de ahorro de agua. Al revés. https://alreves. net.ar/los-glaciares-son-una-caja-de-ahorro-de-agua/

Newenham-Kahindi, A. M. (2011). A Global Mining Corporation and Local Communities in the Lake Victoria Zone: The Case of Barrick Gold Multinational in Tanzania. Journal of Business Ethics, (99), 253-282. https://doi.org/10.1007/s10551-010-0653-4 
Ortiz, A. y López, L. (2011). Control de arroz maleza. Agronomía Tropical, 61(3-4), 199-214.

Pazos, F. (2007). Cultivos no-transgénicos resistentes a herbicidas. Una nueva "solución" de la Industria: la tecnología Clearfield. http://www.rapaluruguay.org/agrotoxicos/Prensa/Cultivos_no-transgenicos_ resistentes_a_herbicidas.pdf

Pestre, D. (2002). Ciencia, dinero y política. Nueva Visión.

Poder Judicial de la Nación. (2017). Causa N`16156/16, caratulada "IANIGLA, SECRETARIA MEDIO AMBIENTE DE LA NACION Y OTROS S/ INCUMPLIMIENTO DEB. FUN. PUB Y OTROS". https://es.slideshare.net/ Unidiversidad/fallo-ley-de-glaciares

Rodríguez-Pardo, J. (2010, 11 de agosto). Glaciares, periglaciares y expertos. Informe especial. Ecoportal. https://www.ecoportal.net/temas-especiales/agua/glaciares_periglaciares_y_expertos_informe_ especial/

Rosas, J. E., Gómez, A., Lago, F. y Macedo, I. (2014). Monitoreo de arroz rojo resistente a imidazolinas en chacras con uso intensivo del sistema Clearfield ${ }^{\circledR}$. ARROZ -SOJA Resultados Experimentales 2012-13. INIA.

Ruiz, L. (2018, 10 de enero). Se amplía el debate sobre la protección de los glaciares. Agencia Ciencia, Tecnología y Sociedad. http://www.ctys.com.ar/index.php?idPage=20\&idArticulo=3498

Schiaffini, H. (2004). La inserción de la inversión en minería en las tendencias socio-económicas de la Argentina. Revista Theomai, (10), 0. http://www.revista-theomai.unq.edu.ar/numero10/artschiaffini10. htm

Schiaffini, H. (201 7, 4-7 de abril). Dos conflictos frente a la minería a cielo abierto. Hegemonía y fuerzas sociales en Esquel y Cerro de San Pedro (ponencia). XIII Reunión de Historiadores de la Minería Latinoamericana. Diálogos y desafíos interdisciplinarios en torno a la minería latinoamericana de ayer y hoy, Buenos Aires, Argentina.

Shaner, D. L. y O'Connor S. L. (1991). The imidazolinone herbicides. CRC Press.

Shivrain, V., Burgos, N., Anders, M., Rajguru, S., Moorey, J. y Sales, M. (2007). Gene flow between Clearfield ${ }^{\mathrm{TM}}$ rice and red rice. Crop Protection, 26(3), 349-356. https://doi.org/10.1016/j.cropro.2005.09.019

Tapia-Baldis, C., Trombotto, D. y Ahumada, A. (2019). Ambiente periglacial y regiones geocriológicas en los Andes de San Juan, Argentina (28 $\left.-33^{\circ} \mathrm{S}\right)$. Revista de la Asociacion Geologica Argentina, 76(1), 43-59. http://hdl.handle.net/11336/119970

Teubal, M. y Rodríguez, J. (2002). Agro y alimentos en la globalización. Una perspectiva crítica. La Colmena.

Varsavsky, O. (1969). Ciencia, política y cientificismo. CEAL.

Viale, E. (2017, 7 de diciembre). Imprescindibles aclaraciones sobre el fallo de Casanello, el IANIGLA y la Ley de Glaciares. La Izquierda Diario. https://www.laizquierdadiario.com/Imprescindibles-aclaracionessobre-el-fallo-de-Casanello-el-IANIGLA-y-la-Ley-de-Glaciares

Villalba, R. (2017a, 23 de agosto). Científico explicó cómo se relevaron los glaciares. Los Andes. https:// www.losandes.com.ar/article/cientifico-explico-como-se-relevaron-los-glaciares

Villalba, R. (2017b, 2 de diciembre). La situación es extraña. Página 12. https://www.pagina12.com. ar/79883-la-situacion-es-extrana

Villalba, R. (2018, 16 de mayo). Inventario Nacional de Glaciares. Un investigador procesado por su trabajo científico. https://nexciencia.exactas.uba.ar/un-investigador-procesado-por-su-trabajo-cientifico 